\title{
Blindness from uveitis in a hospital population in Sierra Leone
}

\author{
M J H Ronday, J S Stilma, R F Barbe, A Kijlstra, A Rothova
}

\begin{abstract}
A retrospective study was conducted to assess the causes of blindness and visual impairment in patients who visited an eye hospital in Sierra Leone, West Africa, in 1989 and 1992. These data were compared with figures from 1981. Throughout the years, senile cataract was the major cause of blindness, followed by uveitis (including onchocerciasis). Uveitis remained the second most important cause of blindness in this population, despite the significant decrease in blindness from onchocerciasis (from $30 \%$ in 1981 to $15 \%$ in 1992). An increasing number of patients with uveitis from nononchocercal origin was observed: almost $10 \%$ of the blindness found in 1992 was due to uveitis of non-onchocercal origin. A reduction in visual handicap in patients with nononchocercal uveitis could be achieved if local hospitals could obtain more accurate diagnoses in these patients.

(Br F Ophthalmol 1994; 78: 690-693)
\end{abstract}

Uveitis is defined as an inflammation of the uveal tract (iris, ciliary body, choroid) from any cause, including a large group of diverse diseases affecting not only the uvea but also the adjacent structures. It is an important matter, for instance it accounts for approximately $10 \%$ of severe visual handicap in the Western world. ${ }^{1}$ In $67 \%$ to $73 \%$ of patients with uveitis a specific diagnosis can be established. ${ }^{23}$ However, data on the epidemiology and aetiology of uveitis as well as the amount of visual disability it causes in Africa are not readily available. ${ }^{47}$ In this study we tried to estimate the frequency of uveitis among other diseases leading to visual loss in patients who visited an eye hospital in Sierra Leone.

Sierra Leone is a small country in West Africa, with four ophthalmologists for its four million inhabitants. The Eye Hospital in Lunsar is one of four eye clinics, serving an area of approximately $32000 \mathrm{~km}^{2}$ in which onchocerciasis or river blindness is endemic. Up to 1992, basic eye care in rural areas was virtually non-existent. Although a mobile team from the hospital visited certain remote areas, it usually only referred patients for cataract or glaucoma surgery. This suggests that many patients visited the hospital on their own initiative rather than through referral.

We conducted a retrospective study among patients who visited the Eye Hospital in 1989 and 1992 , and compared these data with figures from $1981^{5}$ to:

(1) assess the frequency of blindness and low vision;

(2) obtain insight into the role of uveitis in this group of patients;
(3) evaluate the distribution of onchocercal versus non-onchocercal uveitis over the years.

\section{Patients and methods}

In 1981, data of all 7626 new patients consulting the Eye Hospital in Lunsar were collected. ${ }^{5}$ For 1989 and 1992 we restricted this to new patients who consulted the hospital during the first 3 months of the year $(n=1527$ and 1472, respectively).

Visual acuity (VA) was assessed using the Snellen E chart. If a patient had spectacles, optimal VA was recorded. Intraocular pressure was measured with a Schiotz tonometer. A detailed eye examination was performed by an ophthalmic nurse and/or an ophthalmologist in a darkened room, using a slit-lamp and a direct ophthalmoscope. In cases of suspected intraocular disease, an ophthalmologist examined the posterior segments by means of indirect funduscopy.

Uveitis was recorded using the International Uveitis Study Group classification system, which is based on the anatomical location of the inflammation: anterior uveitis (iris and ciliary body), posterior uveitis (choroidea and retina), intermediate uveitis (peripheral retina and pars plana of the ciliary body), and panuveitis (generalised inflammation of the whole uvea). ${ }^{8}$ In a number of patients the anatomical localisation could not be determined. In 1981 this classification system had not yet been defined, thus no comparable data were available from those patients.

All patients were checked for nodules of the skin, and a skin snip from the iliac crest was obtained to check for onchocercal microfilariae. Ocular onchocerciasis was diagnosed according to WHO recommendations ${ }^{9}$ and classified as a separate item in patients with uveitis. For example, ocular onchocerciasis was diagnosed when microfilariae were seen in the anterior chamber or when a typical Ridley fundus was observed. Ocular onchocerciasis was also presumed in cases of microfilariae in the skin snip and no indication of any other cause of uveitis. The anatomical classification of the ocular onchocerciasis was as follows: anterior uveitis: sclerosing keratitis, iritis; posterior uveitis: chorioretinitis, optic atrophy; panuveitis: involvement of both segments.

The diagnosis of toxoplasma chorioretinis was made on clinical grounds and was classified as 'non-onchocercal' uveitis. It concerned patients with one or more healed, focal, pigmented retinal or chorioretinal lesions with well defined borders, with or without an active satellite lesion. Uveitis secondary to trauma was registered as 'trauma'. Other causes of uveitis could not be specified owing to lack of diagnostic tests. Uveitis complicated by cataract and/or 
Table 1 Characteristics of blind patients, Eye Hospital Lunsar, Sierra Leone

\begin{tabular}{|c|c|c|c|c|c|c|}
\hline & \multicolumn{2}{|l|}{1981} & \multicolumn{2}{|l|}{1989} & \multicolumn{2}{|l|}{1992} \\
\hline & $n$ & $\%$ & $n$ & $\%$ & $n$ & $\%$ \\
\hline Blind $($ VA $<3 / 60)$ & $762 / 7626$ & $10 \cdot 5$ & $160 / 1527$ & $10 \cdot 5^{\star}$ & $232 / 1427$ & $16 \cdot 3^{\star}$ \\
\hline Blindness in uveitis patients: & $240 / 762$ & 32 & $50 / 160$ & 31 & $54 / 232$ & 23 \\
\hline Onchocercal & $226 / 240$ & 94 & $39 / 50$ & 78 & $34 / 54$ & 63 \\
\hline Non-onchocercal & $14 / 240$ & 6 & $11 / 50$ & 22 & $20 / 54$ & 37 \\
\hline
\end{tabular}

${ }^{\star} \mathrm{p}<0.001$.

Table 2 Aetiology of blindness among new patients, Eye Hospital Lunsar, Sierra Leone

\begin{tabular}{|c|c|c|c|}
\hline Diagnosis & $\begin{array}{l}1981 \\
(n=762) \\
n(\%)\end{array}$ & $\begin{array}{l}1989 \\
(n=160) \\
n(\%)\end{array}$ & $\begin{array}{l}1992 \\
(n=232) \\
n(\%)\end{array}$ \\
\hline \multirow{10}{*}{$\begin{array}{l}\text { Cataract } \\
\text { Uveitis: } \\
\text { Onchocercal } \\
\text { Non-onchocercal } \\
\text { Corneal opacity } \\
\text { Glaucoma } \\
\text { Refractive error } \\
\text { Optic atrophy and } \\
\text { retinal disorders } \\
\text { Trauma } \\
\text { Other }\end{array}$} & $309(40.5)$ & $62(39)$ & $113(49)$ \\
\hline & $226(30)^{\star}$ & $39(24)^{\star}$ & $34(15)^{\star}$ \\
\hline & $14(2)$ & $11(7)$ & $20(9)$ \\
\hline & $93(12)$ & $20(12 \cdot 5)$ & $25(11)$ \\
\hline & $64(8)$ & $29(18)$ & $37(16)$ \\
\hline & $t$ & $8(5)$ & $9(4)$ \\
\hline & & & \\
\hline & $51(7)$ & $16(10)$ & $12(5)$ \\
\hline & $t$ & $1(<1)$ & $4(2)$ \\
\hline & $5(<1)$ & $9(6)$ & $15(6)$ \\
\hline
\end{tabular}

$\star \chi^{2}$ trend $\mathrm{p}<0.001$

†Not recorded as a separate entity in 1981 .

Several patients had a different diagnosis for each eye, bringing the total percentage of blindness beyond 100 .

glaucoma was listed as 'uveitis'. Visual impairment caused by couching was included in the cataract group.

Blindness was defined as VA less than $3 / 60$ in the better eye, visual impairment as VA less than $6 / 18$ but better than or equal to $3 / 60$ in the better eye, and uniocular blindness as VA less than $3 / 60$ in one eye but better than $6 / 18$ in the other eye. ${ }^{10}$

For statistical analysis the $\chi^{2}$ and $\chi^{2}$ trend tests were used."

\section{Results}

\section{VISUAL HANDICAP}

Blindness was present in $10 \cdot 5 \%(762 / 7626)$ of all new patients visiting the eye Hospital in Lunsar in 1981. This was the same in $1989(160 / 1527)$ but increased to $16.3 \%(232 / 1427)$ in 1992 $(\mathrm{p}<0.001$, Table 1$)$. The causes of blindness are shown in Table 2. Senile cataract was the most frequent cause of blindness throughout the years. Uveitis was the second commonest cause

Table 3 Aetiology of visual impairment and uniocular blindness among new patients, Eye Hospital Lunsar, Sierra Leone

\begin{tabular}{|c|c|c|c|c|c|}
\hline \multirow[b]{2}{*}{ Diagnosis } & \multicolumn{3}{|c|}{ Visually impaired } & \multicolumn{2}{|c|}{ Uniocular blind ${ }^{\star}$} \\
\hline & $\begin{array}{l}1989 \\
(n=307) \\
n(\%)\end{array}$ & $\begin{array}{l}1989 \\
(n=52) \\
n(\%)\end{array}$ & $\begin{array}{l}1992 \\
(n=219) \\
n(\%)\end{array}$ & $\begin{array}{l}1989 \\
(n=75) \\
n(\%)\end{array}$ & $\begin{array}{l}1992 \\
(n=162) \\
n(\%)\end{array}$ \\
\hline $\begin{array}{l}\text { Cataract } \\
\text { Uveitis: }\end{array}$ & $105(31)$ & $13(25)$ & $59(27)$ & $10(13)$ & $41(25)$ \\
\hline $\begin{array}{l}\text { Uveitis: } \\
\text { Onchocercal } \\
\text { Non-onchocercal } \\
\text { Corneal opacity } \\
\text { Trauma } \\
\text { Optic atrophy and retinal disorders } \\
\text { Glaucoma } \\
\text { Refractive error } \\
\text { Other }\end{array}$ & $\begin{array}{l}70(23) \\
13(4) \\
48(16) \\
+ \\
46(15) \\
22(7) \\
+ \\
3(1)\end{array}$ & $\begin{array}{l}11(21) \\
4(8) \\
9(17) \\
1(2) \\
4(8) \\
7(13 \cdot 5) \\
7(13 \cdot 5) \\
6(11 \cdot 5)\end{array}$ & $\begin{array}{l}28(13) \\
17(8) \\
13(6) \\
5(2) \\
13(6) \\
24(11) \\
70(32) \\
22(10)\end{array}$ & $\begin{array}{r}14(19) \\
9(12) \\
18(24) \\
12(16) \\
6(8) \\
6(8) \\
1(1) \\
4(5)\end{array}$ & $\begin{array}{l}8(5) \\
17(11) \\
28(17) \\
25(15) \\
5(3) \\
15(9) \\
2(1) \\
25(15)\end{array}$ \\
\hline
\end{tabular}

$\star$ No data available from 1981. $†$ Not recorded as a separate entity in 1981 . of blindness, followed by corneal opacity (1981), and glaucoma (1989 and 1992).

Visual impairment was diagnosed in $4 \%$ (307/ 7626 ) of new patients in 1981, compared with $3 \%$ $(52 / 1527)$ in 1989 and $15 \%(219 / 1427)$ in 1992 $(\mathrm{p}<0.001)$. Uniocular blindness was not recorded in 1981 . In $1989,5 \%(75 / 1527)$ of the patients suffered from this visual handicap, rising to $11 \%(162 / 1427)$ in $1992(\mathrm{p}<0.001)$. Table 3 shows the causes of visual impairment and uniocular blindness. Uveitis was the second commonest cause of visual impairment in 1981 . It was the major cause of both visual impairment and uniocular blindness in 1989. In 1992, however, refractive errors were the most frequent cause of visual impairment, while cataract was commonest in patients with blindness in one eye. In both groups, uveitis came in third position.

UVEITIS

Uveitis accounted for 32\% (240/762) of blindness in 1981 , compared with $31 \%(50 / 160)$ in 1989 , and $23 \%(54 / 232)$ in 1992 (Table 1 ).

\section{ONCHOCERCAL VERSUS NON-ONCHOCERCAL}

UVEITIS

In 1981, ocular onchocerciasis was responsible for $30 \%(226 / 762)$ of all blindness, gradually descreasing to $24 \%(39 / 160)$ in 1989 and $15 \%$ (34/ $232)$ in $1992(0.01>p>0.001)$. Uveitis from other aetiologies was responsible for $2 \%(14 / 762)$ of blindness in 1981 , increasing to $7 \%(11 / 160)$ in 1989 and $9 \%(20 / 232)$ in $1992(\mathrm{p}<0.001)$, a relative as well as absolute increase (Table 2 ). Table 3 shows a similar decrease in visual loss from onchocerciasis among patients with visual impairment and uniocular blindness.

Among patients with uveitis, onchocerciasis was responsible for $94 \%(226 / 240)$ of blindness in 1981 , decreasing to $78 \%(39 / 50)$ in 1989 and $63 \%$ $(34 / 54)$ in 1992 ( $<<0 \cdot 001)$. Thus, blindness from uveitis of other origins increased from 6\% (14/ 240 ) in 1981 to $37 \%(20 / 54)$ in 1992 (Fig 1).

Most patients with visual loss (VA $<6 / 18$ ) from onchocerciasis presented with panuveitis. In the non-onchocercal group panuveitis was most frequent in 1989, though in 1992 this had changed to anterior uveitis (Table 4).

Visual loss in ocular onchocerciasis caused by secondary glaucoma or cataract or both was found in 28 out of 70 patients (40\%) in 1992. Of these complications, glaucoma was most frequently observed (16/28). In patients with non-onchocercal uveitis a similar number of complications were seen ( 21 out of 54 patients $(39 \%))$, yet this was mostly due to cataract $(12 / 21)$.

\section{PATIENT CHARACTERISTICS}

The average age of all blind patients was 51 years in 1989 and 58 years in 1992; in 1981 the exact ages of the patients were not documented. Figure 2 shows the age distribution among blind patients in 1989 and 1992 . The male:female ratio of blind patients was 1.9 in 1981, 1.7 in 1989, and 1.5 in 1992. In patients who were blind from uveitis the average age was 47 years in 1989 and 


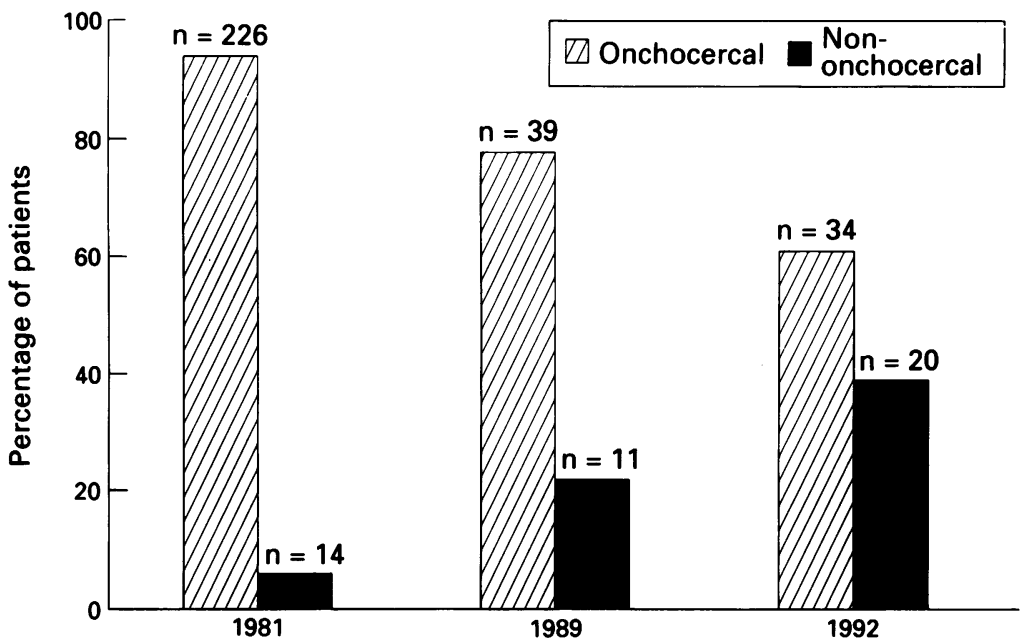

Figure 1 Aetiology of blindness in patients with uveitis, Eye Hospital Lunsar, Sierra Leone. 1981: $n=240,1989: n=50,1992: n=54$.

Table 4 Anatomical localisation of uveitis in visually handicapped patients, ${ }^{\star}$ Eye Hospital Lunsar, Sierra Leone

\begin{tabular}{llllll}
\hline & $\begin{array}{l}\text { Anterior } \\
n(\%)\end{array}$ & $\begin{array}{l}\text { Intermediate } \\
n(\%)\end{array}$ & $\begin{array}{l}\text { Posterior } \\
n(\%)\end{array}$ & $\begin{array}{l}\text { Pan } \\
n(\%)\end{array}$ & $\begin{array}{l}? \\
n(\%)\end{array}$ \\
\hline $\begin{array}{l}\text { Onchocercal uveitis: } \\
8 / 64(12 \cdot 5)\end{array}$ & 0 & & & \\
1989 & $16 / 70(22 \cdot 9)$ & 0 & $1 / 64(1 \cdot 6)$ & $31 / 64(48 \cdot 4)$ & $24 / 64(37 \cdot 5)$ \\
1992 & $3 / 24(12 \cdot 5)$ & 0 & $10 / 70(14 \cdot 3)$ & $40 / 70(57 \cdot 1)$ & $4 / 70(5 \cdot 7)$ \\
$\begin{array}{l}\text { Non-onchocercal uveitis: } \\
1989\end{array}$ & $22 / 54(40 \cdot 7)$ & 0 & $3 / 24(12 \cdot 5)$ & $15 / 24(62 \cdot 5)$ & $3 / 24(12 \cdot 5)$ \\
1992 & $15 / 54(27 \cdot 8)$ & $15 / 54(27 \cdot 8)$ & $2 / 54(3 \cdot 7)$ \\
\hline
\end{tabular}

^Including bilaterally blind, visually impaired, and unilaterally blind patients. ?Anatomical localisation not certain.

54 years in 1992, with an age distribution as shown in Figure 2. The male:female ratio was 3.5 in 1989 and 1.6 in 1992.

In patients with visual impairment, the average age was 47 years in 1989 and 52 years in 1992, while in patients with uniocular blindness the average age was 36 years in 1989 and 40 years in 1992.

\section{Discussion}

This study, conducted at an eye hospital, cannot be taken as being representative of the entire population of Sierra Leone. However, it does inform us as to the causes of visual loss in this

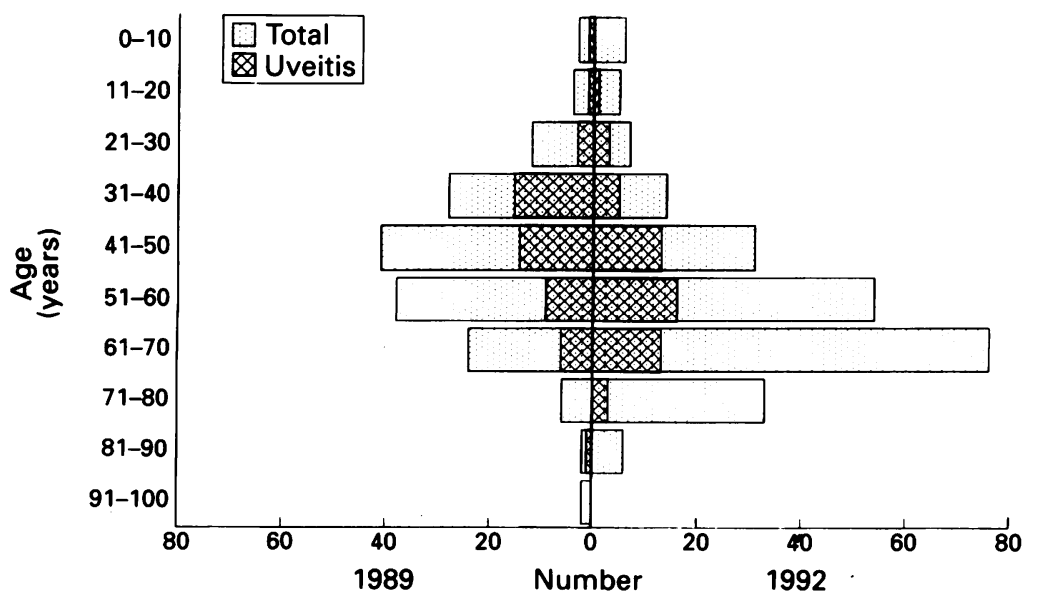

Figure 2 Age distribution among new patients $(V A<3 / 60)$ in 1989 and 1992, Eye Hospital Lunsar, Sierra Leone. area, and the changing patterns observed over the years between 1981 and 1992 .

Our results confirm that cataract is still the major cause of blindness, and that uveitis, including onchocerciasis, comes second. Together they accounted for $73 \%$ of blindness in 1992. Furthermore, our study showed that in the same year one in three patients suffered from visual impairment due to a refractive error.

The average age of patients with a visual handicap attending the hospital increased over the years. In the group of blind patients this was mostly due to an increase in patients aged 61 to 70 years. In patients who were blind from uveitis the average age also increased, but preference for a specific age group was not observed.

Uveitis holds its second position as a cause of blindness despite a significant decrease in blindness from onchocerciasis observed during recent years. The fact that the incidence of onchocerciasis is declining is also confirmed by other authors. ${ }^{1214}$ The use of larvicides in rivers to control the Simulium fly vector as well as the mass distribution of ivermectin since 1989 are the most likely causes of this decline.

The increasing frequency of blindness due to uveitis of non-onchocercal origin to almost $10 \%$ is a surprising finding. An absolute increase of uveitis because of the AIDS pandemic does not seem likely in Sierra Leone; data from our pilot study among patients with uveitis in Sierra Leone revealed HIV positivity in only one out of 144 patients (unpublished). A more likely explanation could be that until recently all cases of uveitis in hyperendemic areas were attributed to onchocerciasis since almost everyone suffered from this systemic disease. A similar phenomenon was seen in Europe in the first half of this century when uveitis was most often attributed to tuberculosis, syphilis, or 'infectious foci' (for example, bad teeth). ${ }^{15}$ If the diagnosis of onchocercal uveitis is based on a positive skin snip alone, it implies a high probability of coincidence and not a direct relation, at least in some patients. It is also possible that in other surveys on blindness complications in uveitis, such as cataract and glaucoma, were considered as direct causes of blindness, while the primary cause (uveitis) remained unmentioned.

The association of uveitis with systemic disease is well known. Reported frequencies from the northern hemisphere vary from $19 \%$ to $46 \% .^{3}$ In tropical countries uveitis is likely to be associated with systemic infections. However, owing to lack of diagnostic equipment in local hospitals, aetiologies of non-onchocercal uveitis remain unknown, and systemic infections are left untreated. This can lead to increased blindness and morbidity, and therefore a shortened life expectancy. ${ }^{16}$

Without doubt, further advances in the struggle against blindness in West Africa would result if, as well as cataract surgery being expanded and the work towards eradication of onchocerciasis continued, other causes of uveitis could be diagnosed more accurately and treated. A study to determine the aetiologies of uveitis in Sierra Leone is in progress.

This study was supported by a grant from the Dr F P Fischer Foundation, IJsselstein, The Netherlands. 
1 Nussenblatt, RB. The natural history of uveitis. Int Ophthalmol 1990; 14: 303-8.

2 Henderly DE, Genstler AJ, Smith RE, Rao NA. Changing patterns of uveitis. Am F Ophthalmol 1987; 103: 131-6.

3 Rothova A, Buitenhuis HJ, Meenken C, Brinkman CJJ, Linssen A, Alberts C, et al. Uveitis and systemic disease. $B r$ F Ophthalmol 1992; 76: 137-41.

4 Yorston D, Foster A, Trebarne J. An unusual uveitis in Tanzanian children. BMF 1989; 299 : 355-7.

5 Stilma JS, Bridger S. Causes and prevalence of blindness in the Northern Province of Sierra Leone. Doc Ophthalmol 1983; 56: 115-22.

6 Whitworth JAG, Gilbert CE, Mabey DM, Morgan D, Foster A. Visual loss in an onchocerciasis endemic community in Sierra Leone. Br f Ophthalmol 1993; 77: 30-3.

7 World Health Organization. Expert committee on onchocerciasis. Third report. WHO Tech Rep Ser 1987; 752: 1-167.

8 Bloch-Michel E, Nussenblatt RB. International uveitis study group recommendations for the evaluation of intraocular inflammatory disease. Am $\mathcal{F}$ Ophthalmol 1987; 103: 234-5.

9 Buck AA. Onchocerciasis: symptomatology, pathology, diagnosis. WHO: Geneva, 1974: 23-30.
10 World Health Organisation. Methods of assessment of avoidable blindness. Geneva: WHO Offset Publications, 1980: able

11 Altman DG. Practical statistics for medical research. London: Chapman \& Hall, 1991: 250-65.

12 Whitworth JAG, Gilbert CE, Mabey DM, Maudec GH, Morgan D, Taylor DW. Effects on repeated doses of ivermectin on ocular onchocerciasis: community-based trial in Sierra Leone. Lancet 1991; 338: 1100-3.

13 Dadzie KY, Awadie K, Bird AC, Schulz-Key H. Ophthalmological results from a placebo controlled comparative 3-dose ivermectin study in the treatment of onchocerciasis. Trop Med Parasitol 1989; 40: 335-60.

14 Rothova A, Van Der Lelij A, Stilma JS, Klaassen-Broekema $\mathrm{N}$, Wilson WR, Barbe RF. Ocular involvement in patients with onchocerciasis after repeated treatment with ivermectin. Am f Ophthalmol 1990; 110: 6-16.

15 Guyton JS, Woods AC. Etiology of uveitis. Arch Ophthalmol 1941; 26: 983-1019.

16 Taylor HR, Katala S, Munoz B, Turner V. Increase in mortality associated with blindness in rural Africa. Bull WHO 1991; 69: 335-8. 